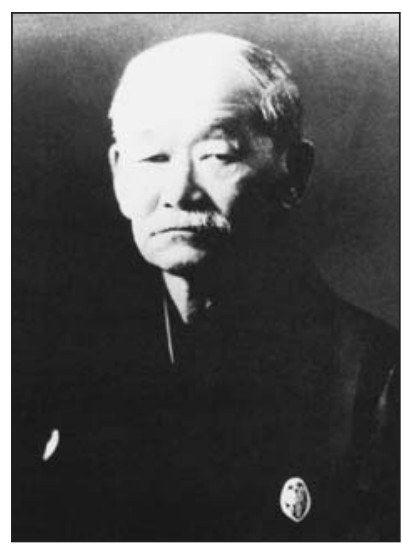

JiGORO KANO

(1860-1938), FUNDADOR DEL JUDO.

\title{
Competición Versus Tradición en el
}

\section{JUDO KODOKAN}

S. BIRON EBELL

$\triangle \nabla$

\section{Resumen}

La asociación del judo con el Comité Olímpico Internacional (COI) y sus patrocinadores corporativos está erosionando la práctica, grandes principios y metas ideadas para el Judo Kodokan por su fundador, jigoro Kano. Con la pretensión de hacerlo accesible a una audiencia televisiva neófita, el judo ha tenido que transformarse en un artículo más comercial. Estos cambios, entre otros, han devaluado el judo recreativo según la opinión de algunos. Este artículo presenta una breve historia evolucionista del judo sobre cómo ha progresado para converger con las necesidades del COI.

\section{Introducción}

Los practicantes de artes marciales orientales a veces se sorprenden de encontrar que las katas (formas preestablecidas [Otaki \& Draeger, 1983: 441]) son realmente parte del Judo Kodokan. Esta creencia parece estar basada en la opinión -probablemente también compartida por el público en general- de que el judo es un deporte, simple y llanamente (Nurse, 2004). Una creencia reforzada aún más por el hecho de que el judo es un deporte olímpico. Con todo, hoy en día la mayoría de las personas generalmente no lo consideran como un arte marcial, y algunos practicantes veteranos de judo no aplicarían en absoluto el término "arte marcial" al judo (Sadej, 1999: 2-3; Schell, 1999: 2-3), a pesar de la obvia conexión histórica del judo con las tradiciones marciales japonesas. Esta visión, creo, puede darse la vuelta cuando se tiene en consideración la historia y el propósito establecido para el judo. De hecho, cuando se considera en detalle, el judo es realmente un budo moderno o camino marcial (Draeger, 1974), cuyo propósito excede con mucho el deporte o la competición. Así, este breve artículo tratará brevemente varios temas importantes entre los que se incluyen:

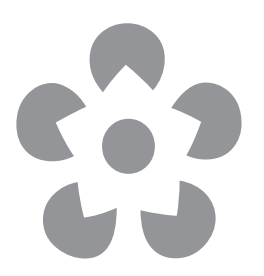

- La fundamentación histórica del judo

- El aprendizaje y la práctica del judo

- Cómo la actual focalización en el judo competitivo está estrechando sus metas y erosionando los principios y prácticas adoptadas por su fundador.

- Cómo las prioridades económicas están conduciendo la evolución del judo lejos de los intereses de la mayoría de sus practicantes.

\section{Historia y propósitos del judo}

El judo, o el Judo Kodokan, como se denomina más correctamente, es una síntesis de varios estilos de jujutsu desarrollada por el visionario y educador japonés del s. XIX Jigoro Kano (1860-1938). Kano nació el 28 de octubre, en Mikage, que es ahora parte de la ciudad de Kobe. En 1874 ingresó en la Escuela de Lenguas Extranjeras de Tokio, donde se especializó en Inglés hasta el punto de que todas sus anotaciones personales, 
y posteriormente sus revistas de budo, estaban escritas en este idioma (Stevens, 1995: 11-12). Irónicamente, ¡sus revistas se han publicado en japonés, pero no en inglés!

En 1877 se convirtió en estudiante de la Universidad de Tokio y fue víctima de "matones" y "rufianes". Fue sobre esta época cuando comenzó a estudiar jujutsu en la Tenshin Shin'yo-ryu bajo la tutela de Hashinosuke Fukuda (1829-1880). Hizo esto a pesar de ser sermoneado por su familia y colegas para que olvidase el jujutsu porque “.. los tiempos han cambiado y tales cosas ya no son útiles” (Stevens, 1995: 14-15). En esta época de la historia, el jujutsu había caído en el descrédito por varias razones, siendo una de las no poco importantes que se había convertido en espectáculo público y de bravucones, perdiendo el honor que ésta y otras artes marciales habían disfrutado durante muchos siglos en Japón (Kano, 2005: 20-21). Sin embargo, el jujutsu de la Tenshin Shin'yo-ryu era nuevo en comparación, pero tenía una reputación de ser un efectivo medio de autodefensa (Draeger, 1974: 113). Se especializaba en atemi waza (técnicas para golpear puntos del cuerpo anatómicamente débiles) y katame o ne-waza (técnicas de control).

Durante el primer año de entrenamiento de Kano su profesor murió, pero él continuó su estudio bajo la dirección de Masamoto Iso (1818-1881), el hijo del fundador de la escuela. Tras el fallecimiento de Iso en 1881, Kano comenzó el estudio del jujutsu de la Kito-ryu bajo la tutela de Tsunetoshi Iikubo (1835-1889). Siendo un arte extremadamente esotérica y filosófica, la Kito-ryu se especializaba en nage waza (técnicas de lanzamiento o proyección) (Kano, 2005: 22-23; Draeger, 1974: 113). En 1883, Iikubo concedió a Kano una licencia para la enseñanza de la Kito-ryu.

En 1882, después de cinco años de diligente estudio, Jigoro Kano estableció su propia arte marcial que llamó "Kodokan judo", sintetizada principalmente del jujutsu de la Tenshin Shin'yo-ryu, Kito-ryu, y otras escuelas. Kodokan se traduce habitualmente como "escuela para estudiar el camino" (Kano et. al., 1986: 16). Adoptó el término "judo" para diferenciar su arte marcial del jujutsu (Kano, 2005: 18-22). Ju implica flexibilidad o adaptabilidad, al igual que sucedía en el jujutsu, pero el sufijo "do" sugiere un propósito más sofisticado para el arte. "Do" es un término esotérico que generalmente implica un camino de vida, un camino de pensamiento, y/o una forma de vivir.

Pero el judo, de ningún modo, surgió completamente formado de la cabeza de Kano. Progresó lentamente desde los conceptos originales de las formas jutsu que había estudiado, y continúa evolucionando hasta hoy en día. Una de sus grandes innovaciones fue diseñar un currículum -una secuencia de estudio organizada y graduada- que aseguraba tanto la estructura como la seguridad para los estudiantes (Donohue, 2005: 26) y un medio eficiente de aprendizaje que se diferenciaba del utilizado en el jujutsu (Kano, 2005: 33-34). Como señala Nurse (2004): "Quizá su mayor innovación [de Kano] fue la enseñanza de los ukemi, o "caídas", antes de que un nuevo estudiante empezase el estudio de la técnica. Esto asegura que cuando un principiante es proyectado, él o ella ya ha aprendido a aterrizar con seguridad y eficientemente sobre las colchonetas sin sufrir daño. Esto constituyó una divergencia significativa respecto a muchos de los sistemas de jujutsu que Kano había examinado previamente, donde los estudiantes eran lanzados -a veces con sus extremidades torcidas deliberadamente, por añadidura- y tenían que aterrizar lo mejor que pudiesen".

\section{La razón de ser del judo de Kano}

Principios y Metas del Judo Kodokan (Kano et. al., 1986: 20-25) establece claramente que los objetivos principales del judo son el bienestar físico, el estudio del ataque y de la defensa, y el entrenamiento moral. Kano (2005: 23) afirma: “... lo he dividido [el judo] en tres partes: su uso como método de combate (arte marcial), como un método de entrenamiento (educación física), y como un método de entrenamiento mental (incluyendo el desarrollo del intelecto y de la moral y la aplicación de judo a la vida diaria)".

Revista de Artes Marciales Asiáticas $\quad$ Volumen 3 Número 2 (28-37) - 2008 


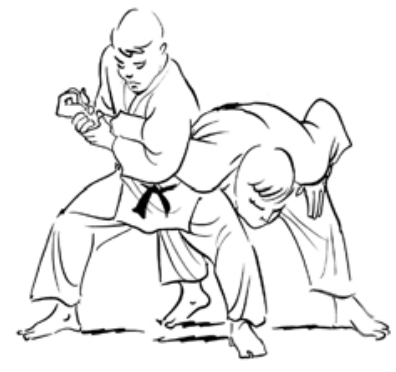

Ilustración por Oscar Ratti. CFuturo Designs $\mathcal{E}$ Publications.
El propósito último del bienestar físico y de la educación física, afirma Kano, es “... hacer fuerte, útil y saludable al cuerpo, mientras se construye el carácter a través de la disciplina mental y moral, ... haciendo un uso eficiente de la energía mental y física... (mientras se progresa) ... hacia la meta de promover la salud, la fuerza, y la utilidad" (Kano et al., 1986: 20). También observó que los deportes eran competitivos por naturaleza, y como tales enfatizan menos un desarrollo físico equilibrado que la consecución de sus metas particulares, mientras que hacen poco o nada por la disciplina moral de sus participantes.

Kano enfatizaba el entrenamiento completo del cuerpo así como el de la fibra moral y mental, para el bien de la sociedad. Observó la forma de lograr esto mientras se aprendían las artes del ataque y la defensa. Para hacerlo de forma segura, los practicantes de judo requieren la cooperación de sus compañeros de entrenamiento. Y para seguir teniendo compañeros con los que entrenar, se debe considerar el bienestar de los otros. Haciendo esto se infunde un sentido de responsabilidad hacia los compañeros de entrenamiento, y por extensión hacia los semejantes. Este importante concepto se concentra en la sentencia de Kano de "jita kyoei" o Bienestar y Beneficio Mutuo, que preconiza "... perfeccionarse a uno mismo y beneficiar al mundo" (Brousse \& Matsumoto, 1999: 84). Por tanto, Kano veía el uso del judo como un medio de lograr un cuerpo sano, un sentimiento moral de respeto mutuo y responsabilidad, y la habilidad para aplicar técnicas de autodefensa si éstas eran requeridas en la vida diaria, utilizando técnicas modificadas de ataque y defensa derivadas del jujutsu.

Otra, pero no menos importante sentencia de Kano fue "seiryoku zenyo", que traducida significa "haciendo que tu energía sea lo más eficiente posible", o "máxima eficiencia", dirige la ejecución física y la comprensión de la técnica de judo. Esta sentencia propone que "... no importa cuál sea la meta, para lograrla, debes poner a trabajar tu energía mental y física del modo más efectivo" (Kano, 2005: 43). En otras palabras: en todos los empeños, ya sea en el judo o en la vida diaria, la eficiencia en la acción y en el pensamiento son consideradas como un ideal.

\section{Judo como deporte}

Refiriéndose al arte moderno de la espada japonesa, el kendo, Kiyota (2002: 1) identifica al deporte como "... una actividad humana estructurada, llevada a cabo en el tiempo de ocio con el propósito de recrear la personalidad humana”. Más adelante, nos dirige a una afirmación de Joseph W. Elder, quien afirma que el deporte incluye tres componentes: competición (con un oponente), actividad física, y reglas establecidas. Si se aceptan estas definiciones, al menos en gran medida la mayor parte del judo se practica realmente como un deporte, pero el arco filosófico y las prioridades morales aducidas por Kano lo diferencian significativamente de otros.

\section{Aprendiendo judo - Randori, Kata y Shiai}

El judo es practicado normalmente de tres formas. Primeramente está el randori. Originalmente, tanto el jujutsu de la Kito-ryu como el de la Tenshin Shin'yo ryu utilizaban el randori, donde "... los dos practicantes no compiten uno contra otro, sino que más bien se entrenan juntos para mejorar su arte. Esto sólo se permitía cuando se había alcanzado la habilidad en la kata" (Kano, et. al., 1986: 141). Y fue en el concepto de randori donde se mostró el genio de Kano. Muchos shin budo (caminos marciales modernos), incluso hoy en día, son practicados fundamentalmente como kata. Kano rompió significativamente con la tradición cuando hizo que el randori fuese una prioridad en el estudio del judo.

Randori es una forma de combate o ejercicio libre, donde los practicantes tienen libertad para practicar sus habilidades de judo frente al oponente que se resiste. El objetivo es desarrollar tanto las tácticas de ataque como las de defensa, pero con las reglas de enfrentamiento del judo. Con el fin de que los estudiantes fuesen capaces de implicarse mutuamente, Kano encontró que era necesario seleccionar y modificar las técnicas del 
jujutsu (waza) de modo que pudieran ser practicadas de modo seguro. Así, fue en 1895 cuando el Kodokan estableció un currículum graduado de técnicas de proyección (nage waza), conocido como el Gokyo no Waza. Fue revisado en 1920 y hoy en día el Kodokan reconoce 67 técnicas de proyección (Daigo, 2005: 9).

¡Idealmente no existen vencedores ni perdedores en el randori! Aquí es donde se desarrollan y perfeccionan las habilidades espirituales y de combate. Como afirman Kano et al. (1986: 142): "La última meta del randori es desarrollar la habilidad de hacer frente rápidamente a circunstancias cambiantes, construir un cuerpo fuerte y flexible, y preparar a la mente y al cuerpo para la competición... Desafortunadamente, en muchos dojos de hoy en día el randori no se practica como debería. Una razón es el énfasis en el entrenamiento para la competición. ... El estilo de judo de competición resultante está muy alejado del ideal".

Con el randori, los practicantes de judo practican sus técnicas sin restricciones, apreciando directamente y sin ninguna duda los efectos completos de sus técnicas. De hecho, el randori diferencia al judo de muchas otras artes marciales, donde los efectos completos de las técnicas deben restringirse por razones de seguridad.

En segundo lugar, el judo se practica como kata. Muchas cosas japonesas se aprenden como shi-kata o "el modo de hacer las cosas" (DeMente, 2003: 1). Esta es una práctica "que ha sido ritualizada o santificada a lo largo de los siglos" (DeMente, 2004: 73). Tradicionalmente, todas las actividades diarias son aprendidas inicialmente a modo de kata, de forma rutinaria o por la práctica repetitiva. Como afirma DeMente (2003: 4): “... los japoneses kata-tizan completamente su existencia. Prácticamente no se deja nada al destino o a la inclinación personal. El factor kata aplicado a todo...”.

Con la kata como presencia formal en la mayoría de comportamientos japoneses, no es extraño encontrar katas en sus artes marciales. En su estima, las katas son formas para ser imitadas, asegurando que un cuerpo preciso de conocimientos se transfiera del profesor al estudiante. Es una especie de plantilla para ser seguida tanto en el aprendizaje como en la ejecución. El judo no es una excepción, ya que las katas son aspectos importantes para el aprendizaje y la práctica

Las katas de judo son formas de ataque y defensa formales y preestablecidas, incluyendo técnicas tales como golpeos que no se permiten en el randori. Es en estas katas donde se aprende y practica el aspecto marcial del judo. Este aspecto del judo no es un deporte. Así, puesto que los practicantes de judo no están en competición en el estudio de la kata, las katas proporcionan la oportunidad de continuar practicando buen judo hasta la senectud (Kano, 2005: 141-142). En judo, por tanto, las katas funcionan para: dirigir la correcta ejecución de la técnica; proporcionar un entorno controlado y predecible donde las técnicas pueden ser practicadas y perfeccionadas; permitir el estudio y práctica de técnicas que tienen una aplicación en la defensa personal; mantener la salud física cuando el entrenamiento para la competición ya no es posible. Y esforzándose para lograr la perfección de la técnica se perfecciona la disciplina y la paciencia.

Pero en el sentido más estricto, los uchi-komi (práctica de ejercicios) también son katas (Otaki \& Draeger, 1983: 40, 482). Es mediante la práctica de los uchi-komi como se aprenden los detalles técnicos básicos de las técnicas. Bajo la estricta supervisión del profesor, la rutina, la algunas veces monótona repetición de técnicas fija las habilidades motrices que son necesarias para que los practicantes de judo ejecuten correctamente las técnicas. A menudo, durante una sesión de entrenamiento, una técnica puede ser repetida cientos de veces. Puesto que los practicantes de judo colaboran en esta forma de práctica, y las acciones están preestablecidas, acordadas, y son repetitivas, este proceso de aprendizaje es una forma de kata.

Para comprender el judo como un arte japonés se requiere estudiar sus katas. Si el judo se considera como un hilo minúsculo en el tapiz de la cultura japonesa, un tapiz que se 


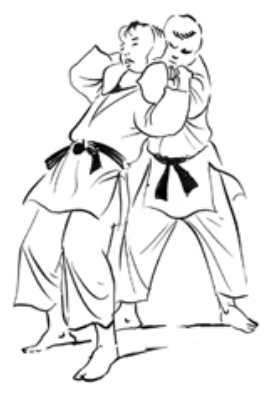

Ilustración por Oscar Ratti.

(C)Futuro Designs $\mathcal{E}$ Publications. aprende como shi-kata, entonces para conocer y comprender el judo en el contexto japonés uno debe conocer y comprender sus katas. En los dojos (lugares de entrenamiento) occidentales, las katas se perciben habitualmente como un obstáculo inconveniente pero necesario para la promoción. DeMente (2003: 14) señala que existe una interesante dicotomía entre la actitud japonesa y occidental hacia las katas: "Los japoneses estaban condicionados tradicionalmente para obtener placer mediante el ajuste a la kata, haciendo las cosas en la manera prescrita. Una de las repercusiones de este condicionamiento fue hacer a los japoneses orientados hacia el proceso en vez de orientados hacia los resultados".

Las sociedades occidentales se afanan hacia los resultados finales claros que marcan simbólicamente la consecución de un trabajo, tal como un diploma universitario o un cinturón negro. Pero, para muchas de las cosas japonesas, el proceso de aprendizaje es prioritario respecto al producto final: en el caso del judo, el estudio diligente y continuado y su práctica es prioritario (al menos en la teoría) sobre el logro de éxitos competitivos o de graduación. Hasta qué punto esto continúa siendo así en la sociedad japonesa de hoy en día es un tema discutible.

En tercer lugar, está el shiai. Es la competición que incluye árbitros, seguimiento de un reglamento, etc. Las propias reglas son más bien complejas. Como en la mayoría de deportes de combate modernos, la victoria es simbólica. En judo, una competición se decide cuando un competidor proyecta con éxito a un oponente, estando en pie, sobre su espalda con velocidad, fuerza e ímpetu. Por esto él o ella recibe un ippon o punto que finalizará el combate. Si el combate continúa en el suelo, puede marcarse un ippon controlando al oponente con su espalda sobre el suelo durante 25 segundos, u obteniendo una sumisión aplicando con efectividad una estrangulación o una luxación, todo con un conciso conjunto de reglas.

El ippon se otorga a técnicas realizadas en competición que presumiblemente incapacitarían o dañarían a un asaltante en una situación de combate incontrolada. Como muchas otras artes marciales, las técnicas de judo eran consideradas efectivas para el combate real. La habilidad para obtener un ippon o un wazari (casi ippon) en combate traduce la capacidad de desarrollar un ataque efectivo, o defenderse uno mismo si fuese necesario -un importante componente histórico del concepto de judo de Kano (Kano, 2005: 23)-.

Antes de 1972 sólo se puntuaban el ippon y el wazari. El lograr un ippon en la competición requería una tremenda determinación y espíritu. No resulta sencillo proyectar o inmovilizar a un oponente que no se deja. Obtener un ippon, era todo o nada. Hoy, no sólo se han reducido los criterios para el ippon -se requieren menos fuerza y velocidad-, sino que se recompensan dos puntuaciones más bajas que el wazari. Por supuesto, los competidores se han adaptado a estas nuevas opciones de puntuación diseñando sus técnicas para lograr estas puntuaciones más bajas y aún así ganar sus combates, un hecho denunciado por algunos (Takahashi, 2005: 20). De hecho, el nuevo régimen de puntuaciones ha reducido el énfasis en el "judo de ippon". Como observa Daigo Toshiro (2003: 151), hoy puedes ser un campeón sin siquiera "hacer un ippon". Asimismo, Kano (2005: 151) observa: "... en la competición o en la pelea, sentirse orgulloso de uno mismo después de ganar sin convencer a tu oponente no cumple con el espíritu del judo. ...Si no ganas utilizando wazas superiores a las que utiliza tu oponente o volviendo sus wazas contra él, no puede decirse que haya sido una verdadera victoria".

Con el reducido énfasis en la competición de "hacer ippones", y las victorias "sin convencer al oponente", uno sólo puede imaginar lo que pasaría si tales técnicas se intentasen en una situación adversa no controlada. Sin "velocidad, fuerza e ímpetu", podría surgir una situación realmente peligrosa. El adversario podría simplemente recuperarse del apuro momentáneo para vengarse causando un serio perjuicio al practicante de judo. De esto puede deducirse que reducir los criterios necesarios para vencer una competición shiai, también reduce las habilidades inherentes del practicante de judo que pueden 
requerirse en el combate real. Es cierto que el Judo Kodokan históricamente ya ha sido apartado cuatro o más veces del realismo del campo de batalla, pero condonar una reducción en los requerimientos para ganar en las competiciones continúa erosionando su ya reducido potencial como medio de ataque y defensa.

\section{El shiai y los campeonatos}

Es en el shiai donde los practicantes de judo aplican todas sus habilidades en un esfuerzo por derrotar a un oponente. El shiai es tradicionalmente una herramienta usada para testar el progreso y la habilidad del practicante de judo contra otros de similares habilidades. Como tal, el shiai proporciona una oportunidad para una evaluación personal y privada del progreso: uno no se preocupa habitualmente por el reconocimiento público. La única persona con un interés personal en el éxito del shiai, aparte del practicante de judo, es su instructor o instructora. El shiai era, y aún es, una ocasión para que los profesores evalúen la técnica, espíritu, y deportividad de los estudiantes. De hecho, un shiai exitoso a veces tiene como resultado que el practicante de judo sea recompensado inmediatamente con un ascenso de grado, conocido como batsugun.

Pero llame usted al shiai "campeonato", y la lógica competitiva cambia. Un "campeonato" establece la escena para el reconocimiento público de las hazañas conseguidas sobre otros. La competición, entonces, se convierte en una afirmación de superioridad entre iguales y ya no es más una herramienta de autoevaluación del progreso en la habilidad. La transformación es sutil, pero significativa, cambiando de una oportunidad para la autoevaluación, como sucede en el shiai, a otra de auto-agrandamiento como reconocido y aclamado campeón (Bowen, 1999: 53). Aunque el objetivo tanto del shiai como del campeonato es vencer, la celebración pública de la victoria cambia el énfasis del éxito personal y privado al reconocimiento público, la adulación y la fama. Y parece que la fama favorece la vanidad humana más que la autosatisfacción.

\section{Héroes deportivos y estatus social}

Saul (1992: 506) menciona que buscar la "excelencia" en el deporte es un intento para ascender en un sistema de clases "con el rey de los mejores en la cima". Es una búsqueda de la celebridad, y nuestra sociedad parece "dar poder a las estrellas" como resultado de la notoriedad pública, sin importar si ésta fue recibida, lograda, o percibida. Respecto a la excelencia deportiva, Saul (ibid.) observa "hemos sido llevados a celebrar la competición como un valor claro como el agua". Lo que Saul parece estar diciendo es que la excelencia deportiva es una forma aceptada de conseguir una fama notable y así escalar dentro de un sistema social ficticio. La realidad es que con casi todos los deportes amateurs -judo incluido- existe poco o ningún beneficio financiero o social derivado del éxito competitivo. Esto es particularmente cierto en el Judo Kodokan, donde existen pocas (si es que hay alguna) oportunidades profesionales pos-heroísmo, y donde la memoria pública del éxito competitivo, si es que éste se comprende, es transitoria en extremo. Ocupar el pedestal del heroísmo crea simplemente el desafío inherente para aquellos que siguen para derrocar al héroe de su lugar preeminente; algo que tendrá que suceder con el tiempo, la edad, y con el reto de la juventud.

La prioridad competitiva ha llevado al judo a evolucionar inexorablemente. El centro administrativo de la Federación Internacional de Judo (IJF), el cuerpo dirigente del judo mundial, continúa concentrándose en el área de la competición. Uno sólo necesita echar una mirada a su página web para inferir que la competición, los resultados competitivos, y los competidores de elite son su prioridad.

Esta prioridad se refleja más aún en las reglas de combate que se han incrementado en complejidad a lo largo del tiempo y en la continua necesidad de articular más claramente cómo se conducen las competiciones. Compare, por ejemplo, las más bien breves 


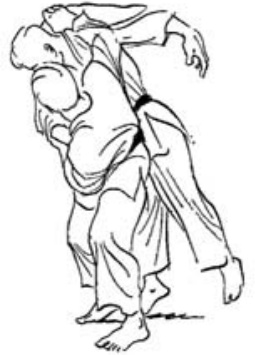

Ilustración por Oscar Ratti. (C)Futuro Designs \& Publications. reglas del Kodokan de 1953 preservadas por Koizumi (1960: 157-165), y Kobayashi y Sharp (1956: 99-102); las reglas de 1961 (Ishikawa \& Draeger, 1962: 291-298); las Reglas de Arbitraje de 1967 (IJF, 1967: 20-22); y las 63 páginas, 14.500 palabras de las "Reglas de Arbitraje" de 2003, como se llaman ahora. Una de las razones por las que las reglas de competición se han vuelto cada vez más complejas es por la necesidad de asegurar la "igualdad de oportunidades" en la competición (Broussse \& Matsumoto, 1999: 42).

Tome por ejemplo la relativamente simple descripción del uniforme de judo que realizan unas tempranas reglas, las cuales describen las dimensiones generales y la composición de la chaqueta, pantalones y cinturón (Koizumi, 1960: 157-165). Contrástelas con las reglas actuales donde se detallan minucias tales como cómo debe ajustarse el traje, grado de superposición de la solapa, longitud de la manga en relación a la longitud del brazo del contendiente, etc. Tales detalles reflejan una lucha inherente entre los practicantes de judo para obtener una pequeña ventaja competitiva sobre sus oponentes, y las reglas que intentan asegurar la "igualdad de oportunidades" de los contendientes.

\section{El Judo y los Juegos Olímpicos}

El judo y el Comité Olímpico Internacional (COI) han disfrutado de una larga asociación. Como dice Nurse (2004): “... en Londres en 1933, el Dr. Kano habló de su deseo de una federación mundial de judo, y de la diseminación de las enseñanzas del Judo Kodokan por todo el mundo como un medio de ayudar a la consecución de la paz mundial. Kano ya había llegado a ser el primer representante japonés en el Comité Olímpico Internacional (1909), así como el primer presidente de la recién formada Asociación Japonesa de Deportes Amateur (1911)". Uno puede comprender fácilmente por qué Kano quería que el judo fuese parte del Movimiento Olímpico, considerando sus similares objetivos. La Carta Olímpica, establecida por Pierre de Coubertin señala:

\footnotetext{
... la meta del Movimiento Olímpico es contribuir a construir un mundo pacífico y mejor, educando a la juventud a través de la práctica deportiva sin discriminación de ningún tipo y en el espíritu Olímpico, que requiere una comprensión mutua con un espíritu de amistad, solidaridad y juego limpio.

... el Olimpismo es una filosofía de vida, exaltando y combinando en una totalidad equilibrada las cualidades del cuerpo, la voluntad y la mente. Mezclando el deporte con la cultura y con la educación, el Olimpismo busca crear un modo de vida basado en la alegría del esfuerzo, el valor educativo del buen ejemplo y el respeto por los principios éticos universales fundamentales.
}

Ambas manifestaciones duplican esencialmente el alto empeño moral del Judo Kodokan y los deseos expresados por Kano de que el judo funcionase para promocionar la paz mundial y el beneficio del mundo (Brousse \& Matsumoto, 1999: 84; Kano, 2005).

El sueño de Kano de que el judo llegase a ser parte de los Juegos Olímpicos se materializó en 1964, cuando las Olimpiadas se realizaron en Tokio. De tal modo comenzó una relación que ha tenido sus ventajas y desventajas para el Judo Kodokan. Como señala Holme (1995: 38): "Justo después de las Olimpiadas de Munich se produjeron los mayores cambios en las reglas. Los poderes existentes se dieron cuenta de que, para atraer patrocinadores, los espectadores de televisión tenían que estar satisfechos".

En relación al papel de los ingresos por publicidad, el mismo COI (2005) observa: "La televisión es el motor que ha conducido el crecimiento del Movimiento Olímpico. Los incrementos en los ingresos por emisión durante las dos últimas décadas han proporcionado al deporte y al Movimiento Olímpico una base financiera sin precedentes.... las retribuciones por los derechos de televisión continúan representando aproximadamente el 50\% de los ingresos olímpicos". 
En relación a los deportes olímpicos participantes, el COI (2005) señala: "Mientras conservan su independencia y autonomía en la administración de sus deportes, las federaciones deportivas internacionales que buscan el reconocimiento del COI deben asegurarse que sus estatutos, prácticas y actividades estén de acuerdo con la Carta Olímpica".

La federación deportiva internacional relacionada con el judo es la IJF. De lo dicho arriba, de la más bien contradictoria declaración del COI, se espera que la IJF siga ciertos criterios para cumplir con las necesidades olímpicas. Además, una de las metas de la IJF es "Apoyar y mantener los ideales y objetivos del Movimiento Olímpico" (IJF, Mission Statement: Aims, 2006).

De las declaraciones anteriores se deduce que uno de estos criterios es asegurar el interés de los televidentes y el soporte de los patrocinadores. Muchos de los cambios de reglas mencionados anteriormente resultan de la necesidad de hacer el judo más amable para el espectador e incrementar su "encanto" (Takahashi et. al., 2005: 7, 15, 17). La IJF ha llegado a grandes extremos para acomodarse a esto (Takahashi et. al., 2005: 7). Por ejemplo, tradicionalmente los contendientes llevaban un cinto blanco o rojo sobre sus cinturones para ayudar a los árbitros a saber quién marcaba qué. Ahora, los contendientes llevan uniformes blancos o azules. Esta innovación fue introducida por la IJF para que fuese más fácil diferenciar a los competidores por televisión, a pesar del disgusto de los practicantes tradicionales de judo japoneses (Takahashi, 2005: 15). Por el lado positivo, el contraste de colores también hace el arbitraje más sencillo". Aunque no parezca tener grandes consecuencias en el combate, los contendientes que llevan el uniforme de judo azul parecen ser estadísticamente los vencedores más a menudo que aquellos que llevan el uniforme blanco tradicional (IJF, 2006/05/04). Los motivos de esto aún se debaten.

Aunque la IJF, no el COI, determina las reglas del deporte, parece que las reglas cambian demasiado frecuentemente. Esto no sólo hace difícil que los propios competidores sepan cuáles son las prácticas y técnicas apropiadas, sino que también los árbitros encuentran dificultades para estar al tanto de los cambios (Holme, 1995: 37-45).

El énfasis colocado actualmente en la excelencia competitiva y en el resultado ha causado que el judo se divida en dos campos diferentes -judo "recreativo" y judo "estilo olímpico o de rendimiento" -. Esta dicotomía conceptual y práctica está teniendo un gran impacto en la práctica del judo (Jones, 2005). Esto es quizá una consecuencia natural de la necesidad de vencer en las arenas olímpicas, produciendo un cambio en las prioridades del entrenamiento, en los métodos y en el enfoque. Como resultado, los atletas entrenan extremadamente duro en ciertas técnicas interrelacionadas que proporcionan la mejor oportunidad para ganar, mientras evaden la mayoría de las 67 (o así) técnicas de judo. De este modo este entrenamiento extremo resulta en un bajo conocimiento del judo en general, en frecuentes lesiones, en una temprana retirada, etc.; el judo contemporáneo, de hecho, ha cambiado su énfasis desde el proceso de aprendizaje hasta la consecución de un fin (De Mente, 2003: 14). Esto está causando una no tan sutil escisión entre los competidores y los practicantes de judo recreativo, que se refleja en las prioridades de los cuerpos dirigentes del judo.

Como señala Jones (2005: 75), el judo recreativo está humillado como algo inferior y, "... los practicantes de judo que prefieren enfocar su estudio en los aspectos más tradicionales y técnicos del judo (por ejemplo en las formas o kata) han sido etiquetados con el rótulo de practicantes recreativos -implicando que son de algún modo inferiores a los practicantes competitivos y no merecedores de atención o reconocimiento-".

Sin embargo, la gran mayoría de practicantes de judo están implicados en una actividad recreativa. En términos de filosofía, el judo recreativo parece igualarse mejor con la tradición del aprendizaje continuo, la salud física, y los ideales morales expuestas por Kano (2005).

Revista de Artes Marciales Asiáticas — Volumen 3 Número 2 (28-37) - 2008 


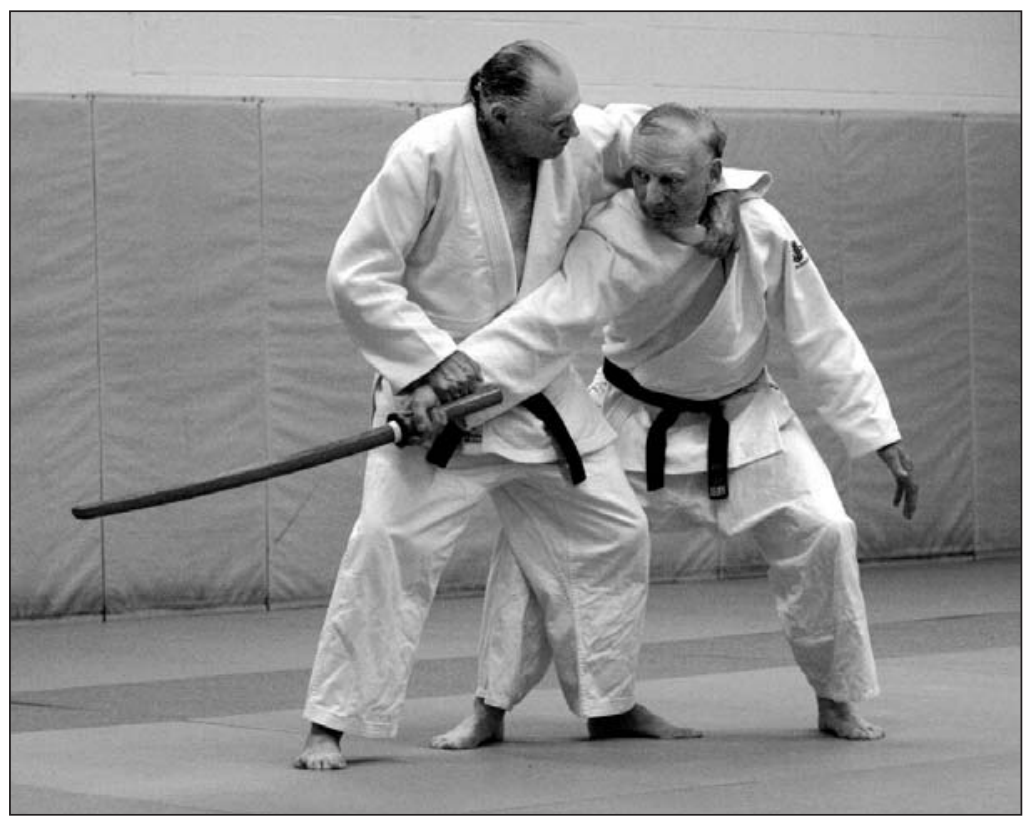

La prioridad competitiva del "Judo Olímpico", deja la desafortunada impresión en los ojos del público de que, con el objeto de participar en el judo, uno debe involucrarse con la competición de élite. Es visto como otro deporte competitivo, y esto parece ser donde se le conduce por último. Sin embargo, el imperativo competitivo desvía la atención de los objetivos primarios del judo establecidos por Kano a finales del s. XIX y principios del XX. Sí, por un proceso normal, el judo ha evolucionado para ser algo diferente de lo que era hace más de 100 años. Pero como se ha mencionado anteriormente, el judo es un componente de la cultura mundial. A diferencia de las especies orgánicas que nacen en el mundo únicamente con sus genes, que los preparan para los caprichos que presenta el

POSICIÓN FINAL DE KIRIOROSHI

(CORTE DESCENDENTE), UNO

DE LOS MOVIMIENTOS DE LA

Kime no Kata (Forma

DE La DeCisión) DEL

Judo Kodokan. TAmbiÉN

CONOCIDA COMO SHINKEN

Shobu no Kata (Formas

DE COMBATE), ESTA KATA

INCORPORA TÉCNICAS DE

ATAQUE Y DEFENSA, TALES

COMO TÉCNICAS DE GOLPEO Y

CONTRAS FRENTE A ATAQUES

ARMADOS, COMO SE MUESTRA

AQUí. El JUDO COMPETITIVO

OLÍMPICO NO PERMITE LOS

GOLPES NI EL USO DE ARMAS.

El CURRICULUM COMPLETO

DEL KodoKan SOlO PUEDE

EXPERIMENTARSE SI SE INCLUYE

LA KATA COMO PARTE DE LA

PRÁCTICA REGULAR DEL JUDO.

Demostrando, Biron Ebell

y Milton Jones (UKE).

Fotografía por Brook Jones. entorno y su evolución o extinción final, los "genes" del judo son sus participantes. Estos "genes" tienen el beneficio de una memoria y un propósito colectivo y, a diferencia de las especies orgánicas, su evolución puede ser dirigida mediante el conocimiento del pasado y la percepción de lo que el judo debería ser en el futuro. Por tanto, en vez de doblegarse a las necesidades de una desinteresada minoría de público televisivo y, a cambio, los beneficios de los anunciantes, el judo debe permanecer como propiedad de todos los practicantes de judo -competidores, practicantes de judo recreativos, y sus profesores-. Todos deberían jugar un papel en determinar cómo debería evolucionar el judo.

Con los cambios de las reglas para acomodar la comprensión del espectador y a los patrocinadores del COI, los representantes nacionales conducidos a la necesidad de vencer, y la pérdida del propósito histórico, el judo está en peligro de cerrar un círculo y llegar a ser lo que el jujutsu fue en el s. XIX. Sin la intervención de los cuerpos dirigentes de judo y de los instructores, existe la probabilidad de asumir el mismo bajo estatus que Kano encontró en el jujutsu de Japón del s. XIX (Kano, 2005: 136). De hecho, el uso del término "arte marcial" en las luchas de jaula de "ground and pound" ["lleva al suelo y golpea"] o en las así llamadas "artes marciales mixtas (MMA)" humilla los altos propósitos no sólo del judo, sino de otros budo habitualmente incluidos en el género de artes marciales. Mantenga en mente que el término arte marcial ha sido usurpado y no está afiliado legítimamente con el tipo de exhibiciones públicas humillantes que se encuentran en los deportes de jaula de las MMA.

Por el contrario, el Judo Kodokan debería aferrarse tenazmente a cualquiera, o a todos los términos: arte marcial, camino marcial, o budo en referencia a sí mismo. Todos estos términos reflejan una gloriosa tradición y unas mayores metas que aquellas que se encuentran meramente en los deportes. Como afirma unívocamente Jhoon Rhee (1998), el padre del taekwondo americano, "Llamo pelea callejera a las artes marciales sin filosofía...”. Las artes marciales orientales se conectan generalmente con códigos morales y éticos que aborrecen la violencia, evitan la utilización y la exhibición pública, y son de algún modo ofendidas o distraídas por el auto engrandecimiento de los así llamados maestros o vencedores de los combates de jaula. Como observa Donohue (1998: 27) “... el auténtico propósito de las artes marciales es forjar el espíritu”. ¡Y así fue, es, y debe seguir siendo para el Judo Kodokan!

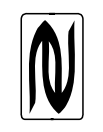




\section{BIBLIOGRAFÍA}

Brousse, M. \& Matsumoto, D. (1999). Judo: A sport and a way of life. Seoul: International Judo Federation.

Daigo, T. (2005). Kodokan Judo throwing techniques. Tokyo: Kodansha International.

DeMente, B. (2003). Kata: The key to understanding and dealing with the Japanese! Boston: Tuttle.

DeMente, B. (2004). The Japanese samurai code: Classic strategies for success. Boston: Tuttle.

Donohue, J. (1998). Herding the ox: The martial arts as moral metaphor. Wethersfield, CT: Turtle Press.

Donohue, J. (2005). Modern educational theories and traditional Japanese martial arts training methods. Journal of Asian Martial Arts, 14(2): 8-29.

Draeger, D. (1974). Modern bujutsu and budo. The martial arts and ways of Japan: Volume 3. New York: Weatherhill.

Holme, P. (1996). Get to grips with judo. Dorset, England: Blandford.

International Judo Federation (2006, 21 de abril). International Judo Federation Mission Statement http://www.ijf.org/rule/rule_role_mission.php\#4

International Judo Federation (2006, 4 de mayo). The color of judogis: Wear blue if you have the choice. http://www.ijf.org/board/board_view.php?Page=1\& SearchSelc $=\&$ SearchText $=\&$ Idx $=293$

International Olympic Committee (2005, 28 de diciembre). The International Olympic Charter. http://www.olympic.org/uk/organisation/missions/charter_uk.asp

Jones, L. (2005). Competition, kata and the art of judo. Journal of Asian Martial Arts, $8(3): 72-85$.

Kano, J. (2005). Mind over muscle: Writings from the founder of judo. Tokyo: Kodansha.

Kano, J., et. al. (1986). Kodokan Judo. Tokyo: Kodansha.

Kiyota, M. (2002). The Shambhala guide to kendo. Boston: Shambhala.

Nurse, P. (2004, 12 de noviembre). The beginnings of Kodokan Judo, 1882-1938. http:\। www.fightingarts.com/reading/article.php?id=53

Otaki, T. \& Draeger, D. (1994). Judo formal techniques: A complete guide to Kodokan Randori no Kata. Boston: Tuttle.

Rhee, J. (1998). The mystic origins of the martial arts. A\&E Home Video. A\&E Television Networks.

Sadej, A. (1999). Should we promote judo as a martial art? Commentary in: Yudansha Journal: Official Publication of Judo Canada, 5(1): 2-3.

Saul, J. (1992). Voltaire's bastards: The dictatorship of reason in the west. New York: Penguin Books.

Schell, C. (1999). Commentary in: Yudansha Journal: Official Publication of Judo Canada, $5(2): 2-3$.

Sidney, J. (Ed.) (2003). The warrior's path: Wisdom from contemporary martial arts masters. Boston: Shambhala.

Stevens, J. (1995). Three budo masters. Tokyo: Kodansha.

Takahashi, M. \& Family. (2005). Mastering judo. Champaign, IL: Human Kinetics.

\section{AGRADECIMIENTO}

El autor expresa un especial agradecimiento

a Milton Jones ( $3^{\text {er }}$ dan) y a Henry Epp ( $6^{\circ}$ dan),

quienes leyeron y comentaron los primeros borradores de este manuscrito. 